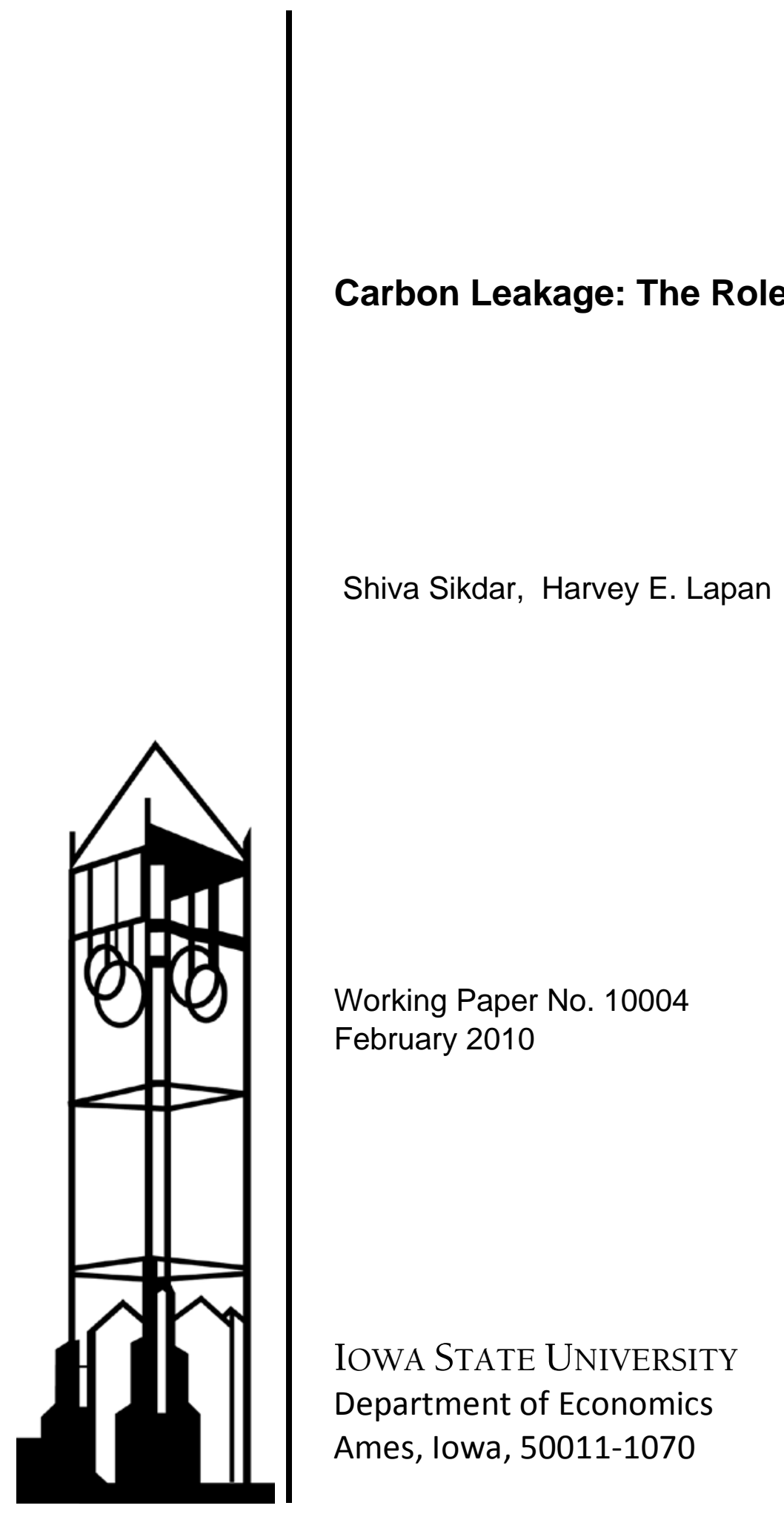

lowa State University does not discriminate on the basis of race, color, age, religion, national origin, sexual orientation, gender identity, sex, marital status, disability, or status as a U.S. veteran. Inquiries can be directed to the Director of Equal Opportunity and Diversity, 3680 Beardshear Hall, (515) 294-7612. 


\title{
Carbon Leakage: The Role of Sequential Policy Setting
}

\author{
Shiva Sikdar* \\ Yonsei University
}

\author{
Harvey E. Lapan ${ }^{\dagger}$ \\ Iowa State University
}

April 15, 2010

\begin{abstract}
We analyze non-cooperative environmental policy when the only strategic interaction between countries is through bilateral transboundary pollution, i.e., countries are closed or small open economies. When countries set pollution taxes simultaneously, there is no carbon leakage. However, in the sequential-move game, the leader sets its pollution tax lower than the marginal damage from own pollution and lower than that in the simultaneous-move game, while the follower sets its tax higher than that in the simultaneous-move game. The only motive behind the leader's underregulation of own pollution is to reduce the incidence of transboundary pollution from the follower, i.e., to reduce carbon leakage. Aggregate pollution is higher in the sequential-move game than in the simultaneous-move game if pollution is a pure global public bad.
\end{abstract}

JEL classification codes: Q58, H23.

Key words: Carbon leakage; Sequential-move game; Strategic environmental policy; Transboundary pollution.

*Sikdar: EIC, Yonsei University, Jeongui Gwan 338, 234 Maeji, Heungup, Wonju, Gangwondo, South Korea 220-710; Tel: +82 (33) 760-2716; FAX: +82 (33) 760-2712; E-mail address: shivasikdar@gmail.com.

${ }^{\dagger}$ Lapan: Department of Economics, Iowa State University, 283 Heady Hall, Ames, IA 50011, USA; Tel: +1 (515) 294-5917; FAX: +1 (515) 294-0221; E-mail address: hlapan@iastate.edu. 


\section{Introduction}

Governments in large countries may distort domestic environmental policy in the presence of transboundary pollution to reduce carbon leakage, which occurs when strict domestic pollution policy increases foreign emissions. A change in domestic policy in a large country, under trade, changes the world price of the pollution intensive good, leading to a change in production (hence, pollution) in the other country. Rauscher (1997) finds that in large countries with "substantial leakage effects, optimal environmental policies tend to lead to too low emission tax rates" when the pure terms of trade effects are small compared to leakage effects. To the best of our knowledge, in the literature, carbon leakage has only been shown to occur in large countries under trade as changes in pollution policies in closed or small open economies do not affect world prices, through which carbon leakage works.

Most papers in the literature on trade and environmental policy ${ }^{1}$ focus on the policy choice of large countries (which can influence world prices). Markusen (1975), Copeland (1996) and Hatzipanayotou et al. (2008) are some of the papers that analyze non-cooperative pollution policy in small open economies when there is transboundary pollution and countries set their policies simultaneously. However, it is well known that strategic considerations come in to effect when policy is set sequentially ${ }^{2}$. In this note, we consider environmental policy in neighboring countries that cannot influence world prices and suffer from bilateral transboundary pollution. To focus on the effect of sequential policy setting on pollution policy in the presence of a bilateral transboundary externality, we assume that neither country can manipulate its terms of trade ${ }^{3}$.

Bárcena-Ruiz (2006) analyzes first-mover advantages in setting environmental policy in the presence of imperfect competition when there is transboundary pollution between two large policy active countries" ${ }^{4}$ The "rent capture effect" lowers pollution taxes in each country, while the "sequential setting effect" increases taxes in both countries. He finds that, when transboundary spillovers are low (high), the leader sets a higher (lower) tax than the follower. Our analysis departs from the large country assumption of Bárcena-Ruiz; hence, countries have no incentives to distort environmental policy for terms of trade objectives. Furthermore, in our model, all sectors in both countries are perfectly competitive and there

\footnotetext{
${ }^{1}$ See, for instance, Copeland and Taylor (2004) for a comprehensive and critical review of issues related to trade and the environment.

${ }^{2}$ See, for example, Tirole (1989) and Gal-Or (1985).

${ }^{3}$ As Hatzipanayotou et al. (2008) notes, "countries in the European Union or in other RTAs are part of a much bigger world trading system. Therefore, the assumption regarding the exogeneity of terms of trade between any two such countries may not be an implausible one".

${ }^{4}$ In a similar setting, Kennedy (1994) analyzes strategic interaction between governments that set pollution taxes simultaneously when there is transboundary pollution and imperfect competition.
} 
is no "rent capture" motive.

One can think of bilateral transboundary pollution in terms of water bodies shared between countries ${ }^{5}$. Release of effluents in such waters by neighboring countries affects only these countries, resulting in bilateral transboundary pollution. Such problems have been observed worldwide, including the well known dispute regarding paper mills set up on the Uruguay side of the Uruguay river, which resulted in Argentina appealing to the International Court of Justice ${ }^{6}$. Hence, our analysis would be most relevant to these kinds of transboundary pollution problems.

We find that when the only strategic interaction between countries is via transboundary pollution and pollution taxes are set simultaneously, there is no carbon leakage. But, in a sequential-move game there is carbon leakage even if neither country can influence world goods prices: if the leader sets a high pollution tax, it leads to higher emissions in the follower, which, in turn, reduces the leader's welfare via increased incidence of transboundary pollution. This lowers the leader's marginal benefit from regulating pollution. The leader's pollution tax is lower than that in the simultaneous-move equilibrium and lower than the marginal damage from own pollution. The only motive behind the leader's underregulation of pollution is to reduce carbon leakage. If there is only unidirectional transboundary pollution flow, carbon leakage does not occur and, the sequential and simultaneous move equilibria coincide. Moreover, if pollution is a pure global public bad, then aggregate pollution is higher in the sequential-move game than in the simultaneous-move game.

In the next section, we present the model, derive efficient pollution taxes and noncooperative taxes under simultaneous-move. Section 3 analyzes the sequential-move game. Section 4 concludes.

\section{Model}

We consider two neighboring countries, home and foreign countries (foreign variables are denoted using $\mathrm{a}^{*}$ ) affected by bilateral transboundary pollution. The rest of the world (assumed not to behave strategically) does not generate pollution that affects these countries nor is it affected by pollution from the latter; pollution in water bodies shared between countries would be such a case. There are two goods $(X, Y)$ that are produced under

\footnotetext{
${ }^{5}$ The Great Lakes shared between the United States and Canada, Lake Albert between Uganda and the Democratic Republic of Congo, and Lake Constance bordered by Austria, Germany and Switzerland are a few examples. Many rivers flow across different countries, for instance, the Ganges through India and Bangladesh, the Indus through India and Pakistan, the Nile through Egypt and Sudan, and the Uruguay river forms the border between Argentina and Uruguay.

${ }^{6}$ Some other examples of transboundary water pollution include Lake Titicaca shared by Bolivia and Peru, and Lake Peipsi between Estonia and Russia.
} 
perfectly competitive conditions and consumed in these two countries.

Home and foreign feasible production sets are, respectively,

$$
g(x, y, z ; \vec{V}) \leq 0 \quad \text { and } \quad g^{*}\left(x^{*}, y^{*}, z^{*} ; \vec{V}^{*}\right) \leq 0 ; \quad g_{x}, g_{y}, g_{x^{*}}^{*}, g_{y^{*}}^{*} \geq 0>g_{z}, g_{v_{i}}, g_{z^{*}}^{*}, g_{v_{i}^{*}}^{*}
$$

where $z\left(z^{*}\right)$ is home (foreign) emission and $\vec{V}\left(\vec{V}^{*}\right)$ is the home (foreign) country's factor endowment vector. This specification nests the case in which pollution is generated as a by-product of production of either or both goods. It also allows for substitutability between inputs that can reduce emissions, the possibility of abatement and having polluting as well as non-polluting inputs.

Preferences of the representative agent in the home and foreign countries are, respectively,

$$
U\left(c_{x}, c_{y}, z, z^{*}\right)=\psi\left(c_{x}, c_{y}\right)-\phi\left(z, z^{*} ; \alpha\right) \text { and } U^{*}\left(c_{x}^{*}, c_{y}^{*}, z^{*}, z\right)=\psi^{*}\left(c_{x}^{*}, c_{y}^{*}\right)-\phi^{*}\left(z^{*}, z ; \beta\right),
$$

where $c_{x}\left(c_{x}^{*}\right)$ and $c_{y}\left(c_{y}^{*}\right)$ denote consumption of $X$ and $Y$ in the home (foreign) country; $\psi($.$) and \psi^{*}($.$) are twice differentiable and concave. Pollution damage functions in both$ countries, $\phi($.$) and \phi^{*}($.$) , are strictly convex in emissions and the marginal damage in each$ country is increasing in emissions of either country. Hence, $\phi_{z}, \phi_{z^{*}}, \phi_{z z}, \phi_{z z^{*}}, \phi_{z^{*} z^{*}}>0$ and $\phi_{z^{*}}^{*}, \phi_{z}^{*}, \phi_{z^{*} z^{*}}^{*}, \phi_{z z^{*}}^{*}, \phi_{z z}^{*}>0 ; \alpha$ and $\beta$ are shift parameters that will be used later ${ }^{7}$. Furthermore, the marginal damage from own pollution is at least as high as that from transboundary pollution in both countries, i.e., $\phi_{z} \geq \phi_{z^{*}}$ and $\phi_{z^{*}}^{*} \geq \phi_{z}^{*}$. A pollution damage function, commonly used in the literature, that satisfies the above properties is $\phi\left(z, z^{*}\right)=\frac{\eta}{2}\left(z+\lambda z^{*}\right)^{2}$, $\eta>0, \lambda \leq 1$.

Suppose that both countries use taxes on own emissions, $\hat{t}$ and $\hat{t}^{*}$, which are the only policy instruments available, to regulate pollution. Let $Y$ be the numeraire good, i.e., set the price of $Y, p_{y} \equiv 1$, and denote the price of $X$ as $p$. The GNP functions for the home and foreign countries $\operatorname{are}^{8}$, respectively,

$$
R(p, \hat{t}) \text { and } R^{*}\left(p^{*}, \hat{t}^{*}\right)
$$

Home and foreign expenditure functions are ${ }^{9}$, respectively,

$$
e\left(p, u+\phi\left(z, z^{*}\right)\right) \quad \text { and } \quad e^{*}\left(p^{*}, u^{*}+\phi^{*}\left(z, z^{*}\right)\right) .
$$

\footnotetext{
${ }^{7}$ We suppress these notations, $\alpha$ and $\beta$, and use them only when required for future analysis.

${ }^{8}$ The GNP function is given by $R(p, \hat{t})=\max _{x, y, z}\{p x+y-\hat{t} z\}$ such that $g(x, y, z ; \vec{V}) \leq 0$. Standard envelope properties of this function imply $R_{\hat{t}}=-z$ and $R_{\hat{t} \hat{t}}=-z_{\hat{t}}$.

${ }^{9}$ Due to the presence of the externality, the expenditure function is given by: $\min _{c_{x}, c_{y}}\left(p c_{x}+\right.$ $\left.c_{y}\right)$ s.t. $\psi\left(c_{x}, c_{y}\right)-\phi\left(z, z^{*}\right) \geq u \Rightarrow \min _{c_{x}, c_{y}}\left(p c_{x}+c_{y}\right)$ s.t. $\psi\left(c_{x}, c_{y}\right) \geq u+\phi\left(z, z^{*}\right)$.
} 
The resource constraints for the home and foreign countries are, respectively,

$$
\begin{aligned}
e\left(p, u+\phi\left(z, z^{*}\right)\right) & =R(p, \hat{t})+\hat{t} z \\
\text { and } \quad e^{*}\left(p^{*}, u^{*}+\phi^{*}\left(z, z^{*}\right)\right) & =R^{*}\left(p^{*}, \hat{t}^{*}\right)+\hat{t}^{*} z^{*},
\end{aligned}
$$

where we have assumed that all tax revenues are rebated back lump-sum to the consumers. Differentiating eq. (1) with respect to $\hat{t}$, we get the best response function of the home country as a function of the foreign country's tax:

$$
e_{u} \frac{d u}{d \hat{t}}=\left(R_{p}-e_{p}\right) \frac{d p}{d \hat{t}}+\left(\hat{t}-e_{u} \phi_{z}\right) \frac{d z}{d \hat{t}}-e_{u} \phi_{z^{*}} \frac{d z^{*}}{d \hat{t}} .
$$

The first term reflects the terms of trade effect; it depends on the relative pollution intensity of $X$ and the direction of trade. The second term is the welfare effect of a change in $\hat{t}$ via change in domestic emissions. The last term reflects the role of carbon leakage, which can occur through a change in the world price of the pollution intensive good due to a change in the home country's pollution tax; this occurs if countries are economically interdependent and the world prices of goods are endogenous ${ }^{10}$. Carbon leakage can also occur if foreign pollution changes due to a change in marginal damage from own pollution in the foreign country as the home country's pollution tax changes. This latter channel is the only driving force in our model, as will be clear later. The foreign country's best response function as a function of the home country's tax is

$$
e_{u^{*}}^{*} \frac{d u^{*}}{d \hat{t}^{*}}=\left(R_{p^{*}}^{*}-e_{p^{*}}^{*}\right) \frac{d p^{*}}{d \hat{t}^{*}}+\left(\hat{t}^{*}-e_{u^{*}}^{*} \phi_{z^{*}}^{*}\right) \frac{d z^{*}}{d \hat{t}^{*}}-e_{u^{*}}^{*} \phi_{z}^{*} \frac{d z}{d \hat{t}^{*}} .
$$

Assumption. Both home and foreign countries are small open economies and hence $\frac{d p}{d \hat{t}}=$ $\frac{d p^{*}}{d \hat{t}^{*}}=0\left\{\right.$ or, alternatively, both are closed economies and hence $R_{p}=e_{p}$ and $\left.R_{p^{*}}^{*}=e_{p^{*}}^{*}\right\}$.

This implies that there is no terms of trade effect; hence, the only strategic interaction between countries is through transboundary pollution ${ }^{11}$. Eqs. (3) and (4) imply that, in the absence of transboundary pollution, the optimal home and foreign taxes are, respectively,

$$
\bar{t}=e_{u} \phi_{z}\left(z, z^{*}\right) \quad \text { and } \quad \bar{t}^{*}=e_{u^{*}}^{*} \phi_{z^{*}}^{*}\left(z, z^{*}\right)
$$

\footnotetext{
${ }^{10}$ See, among others, Rauscher (1997) and Lapan and Sikdar (2010).

${ }^{11}$ Kiyono and Okuno-Fujiwara (2003) also consider a model where the only interaction between two closed economies is through "global warming", but governments set environmental policy simultaneously, although firms may move second to make production decisions.
} 
i.e., each country sets its emission tax equal to its own marginal damage and this is Pareto efficient since there is no transboundary externality. Hereafter, we explicitly assume transboundary pollution occurs.

Pareto Efficient Taxes. The Pareto efficient pollution taxes ${ }^{12}$ in the home and foreign countries are, respectively,

$$
t^{e}=e_{u} \phi_{z}+e_{u^{*}}^{*} \phi_{z}^{*} \quad \text { and } \quad t^{e *}=e_{u^{*}}^{*} \phi_{z^{*}}^{*}+e_{u} \phi_{z^{*}}
$$

i.e., the efficient pollution tax equals the sum of marginal damages in the two countries. Hence, efficiency requires that both countries internalize the domestic and transboundary effects of their emissions.

Simultaneous-Move Pollution Taxes. When countries set taxes simultaneously and noncooperatively, since $\frac{d z^{*}}{d \hat{t}}=\frac{d z}{d \hat{t}^{*}}=0$, eqs. (3) and (4) imply that the optimal pollution taxes are

$$
\hat{t}=e_{u} \phi_{z}\left(z, z^{*}\right) \quad \text { and } \quad \hat{t}^{*}=e_{u^{*}}^{*} \phi_{z^{*}}^{*}\left(z, z^{*}\right)
$$

There is no strategic interaction in the simultaneous-move game and each country sets its pollution tax equal to the marginal damage from its own pollution. Comparing eqs. (6) and (7), it is clear that in the simultaneous-move game, the pollution taxes, although optimal from each country's perspective, are inefficient from the global perspective as countries do not internalize the transboundary effects of their emissions.

\section{Sequential-Move Pollution Taxes}

We now consider the case where the home country moves first; denote the home and foreign taxes in the sequential-move game by $t$ and $t^{*}$, respectively. The foreign country (follower) still sets its tax equal to the marginal damage from its own emissions (since $\frac{d z}{d t^{*}}=0$ ):

$$
\frac{d u^{*}}{d t^{*}}=0 \Rightarrow J^{*}\left(t^{*}, t, \beta\right)=t^{*}-e_{u^{*}}^{*} \phi_{z^{*}}^{*}\left(z^{*}\left(t^{*}\right), z(t), \beta\right)=0
$$

However, now the leader (home country) can influence foreign emissions by strategic choice of its pollution tax, i.e., $\frac{d z^{*}}{d t} \neq 0$. Since $z=-R_{t}$ and $z^{*}=-R_{t^{*}}^{*}$, we have

$$
\frac{d z}{d t}=-R_{t t} \quad \text { and } \quad \frac{d z^{*}}{d t}=\frac{d z^{*}}{d t^{*}} \frac{d t^{*}}{d t}=-R_{t^{*} t^{*}}\left(\frac{d t^{*}}{d t}\right) .
$$

\footnotetext{
${ }^{12}$ These are obtained by solving a social planner's problem that maximizes one country's welfare subject to meeting a certain utility target for the other country.
} 
We make the simplifying assumption that $e_{u^{*} u^{*}}^{*}=0$, i.e., the marginal utility of income is constant. Differentiating eq. (8) w.r.t. $t$, we have, using eq. (9),

$$
\frac{d t^{*}}{d t}=\frac{-J_{t}^{*}\left(t^{*}, t, \beta\right)}{J_{t^{*}}^{*}\left(t^{*}, t, \beta\right)}=\frac{-e_{u^{*}}^{*} \phi_{z^{*} z}^{*} R_{t t}}{1+e_{u^{*}}^{*} \phi_{z^{*} z^{*}}^{*} R_{t^{*} t^{*}}^{*}}<0,
$$

i.e., the foreign country's pollution tax is decreasing in the home country's pollution tax; this is carbon leakage at work. Using eqs. (9) and (10), we have

$$
\begin{gathered}
\frac{d z^{*}}{d t}=\frac{e_{u^{*}}^{*} \phi_{z^{*} z}^{*} R_{t t} R_{t^{*} t^{*}}^{*}}{1+e_{u^{*}}^{*} \phi_{z^{*} z^{*}}^{*} R_{t^{*} t^{*}}^{*}}>0 \\
\text { and } \frac{d z^{*}}{d z}=\frac{d z^{*}}{d t} \frac{d t}{d z}=\frac{-e_{u^{*}}^{*} \phi_{z^{*}}^{*} R_{t^{*} t^{*}}^{*}}{1+e_{u^{*}}^{*} \phi_{z^{*} z^{*}}^{*} R_{t^{*} t^{*}}^{*}} \in(-1,0)
\end{gathered}
$$

Hence, foreign pollution increases as the home pollution tax increases. This increased inflow of transboundary pollution due to carbon leakage reduces the home country's marginal benefit from regulating its own pollution. Eq. (12) basically implies that home and foreign pollution are strategic substitutes. The home country's best response function, eq. (3), implies:

$$
\frac{d u}{d t}=0 \Rightarrow K\left(t, t^{*}, \alpha\right)=\left(t-e_{u} \phi_{z}\right)-\delta_{s} e_{u} \phi_{z^{*}} \frac{R_{t^{*} t^{*}}^{*}}{R_{t t}} \frac{d t^{*}}{d t}=\left(t-e_{u} \phi_{z}\right)+\delta_{s} e_{u} \phi_{z^{*}} \frac{R_{t^{*} t^{*}}^{*}}{R_{t t}} \frac{J_{t}^{*}}{J_{t^{*}}^{*}},
$$

where $\delta_{s}=0$ in the simultaneous-move game and $\delta_{s}=1$ in the sequential-move game (when the home country moves first). The solution for the simultaneous-move game, $\hat{t}$ and $\hat{t}^{*}$, comes from solving eqs. (8) and (13), assuming $\delta_{s}=0$. On the other hand, in the sequential-move game, the solution, $t$ and $t^{*}$, comes from solving eqs. (8) and (13), assuming $\delta_{s}=1$. The optimal pollution tax for the home country (leader) is:

$$
t=e_{u} \phi_{z}-\underbrace{e_{u}}_{>0} \underbrace{\phi_{z^{*}}}_{>0}\left(\frac{\overbrace{e_{u^{*}}^{*}}^{>0} \overbrace{\phi_{z^{*} z}^{*}}^{>0} \overbrace{R_{t^{*} t^{*}}^{*}}^{>0}}{1+\underbrace{e_{u^{*}}^{*}}_{>0} \underbrace{\phi_{z^{*} z^{*}}^{*}}_{>0} \underbrace{R_{t^{*} t^{*}}^{*}}_{>0}}\right)=e_{u} \phi_{z}\left[\frac{1+e_{u^{*}}^{*} R_{t^{*} t^{*}}^{*}\left\{1-\frac{\phi_{z^{*}} \phi_{z^{*} z}^{*}}{\left.\phi_{z} \phi_{z^{*} z^{*}}^{*}\right\} \phi_{z^{*} z^{*}}^{*}}\right.}{1+e_{u^{*}}^{*} \phi_{z^{*} z^{*}}^{*} R_{t^{*} t^{*}}^{*}}\right] .
$$

Pollution taxes under simultaneous and sequential moves can be compared as follows:

Proposition 1. When countries that cannot influence world prices and are affected by bilateral transboundary pollution set pollution taxes sequentially, the leader underregulates pollution as compared to the simultaneous-move game, i.e., $t<\hat{t}$, and sets its pollution tax lower than the marginal damage from own pollution, i.e., $t<e_{u} \phi_{z}$. The follower sets its pollution tax higher than that in the simultaneous-move game, i.e., $t^{*}>\hat{t}^{*}$. 
Proof. Using eq. (8), define the foreign country's reaction function as $t^{*}=B(t, \beta)$; eq. (10) implies $\frac{d t^{*}}{d t}=B_{t}<0$. Substituting the reaction function in eq. (13), define (since $\delta_{s}=1$ ):

$$
\frac{d u}{d t}=0 \Rightarrow L(t, \beta, \alpha) \equiv K\left(t, t^{*}(t, \beta), \alpha\right)=t-e_{u} \phi_{z}+\frac{R_{t^{*} t^{*}}^{*}}{R_{t t}} \frac{J_{t}^{*}}{J_{t^{*}}^{*}}=0
$$

The second order conditions imply $\frac{d L}{d t}>0$. Furthermore, evaluating the above equation at $t=\hat{t}$ we have $t^{*}(t)=\hat{t}^{*}$; hence, $L(\hat{t})>0$. Given $L_{t}()>$.0 , this implies that the optimal solution $t<\hat{t}$. Finally, the negative slope of the foreign country's reaction function implies that $t^{*}>\hat{t}^{*}$.

Q.E.D.

As the leader's emissions increase $(z \uparrow)$, the follower's marginal damage from own pollution also increases $\left(\phi_{z^{*}}^{*} \uparrow\right.$ since $\left.\phi_{z^{*} z}^{*}>0\right)$. This prompts lower foreign emissions (and a higher foreign pollution tax), which reduces the incidence of transboundary pollution in the leader. Moreover, assuming symmetry ${ }^{13}$, from Proposition 1 , we have

Lemma 1. If countries are symmetric, the leader sets a lower pollution tax than the follower.

If pollution is a pure global public bad, i.e., in both countries, the marginal damage from own pollution is positive and the same as that from the incidence of transboundary pollution, then $\phi_{z}=\phi_{z^{*}}$ and $\phi_{z}^{*}=\phi_{z^{*}}^{*}$, which implies $\phi_{z z^{*}}^{*}=\phi_{z^{*} z^{*}}^{*}$. Hence, from eq. (14) we have

$$
t=\frac{e_{u} \phi_{z}}{1+e_{u^{*}}^{*} \phi_{z^{*} z^{*}}^{*} R_{t^{*} t^{*}}^{*}} \in(0, \hat{t}), \quad \text { i.e. }
$$

Lemma 2. If pollution is a pure global public bad, then the leader's pollution tax is always positive.

Eq. (14) also implies that, if $\phi_{z^{*}}=0$ or $\phi_{z^{*} z}^{*}=0$, then $t=e_{u} \phi_{z}$, i.e., the simultaneousmove and sequential-move equilibria are the same and the leader also sets its tax equal to the marginal damage from own pollution. If transboundary pollution is unidirectional ${ }^{14}$, i.e., if $\phi_{z^{*}}=0$ or $\phi_{z}^{*}=0$, this condition is satisfied. $\phi_{z^{*}}=0$ implies that the leader is not affected by foreign pollution. Since the only incentive behind the underregulation of pollution is to reduce the inflow of transboundary pollution, in the absence of transboundary pollution, the leader does not have any incentive to distort domestic environmental policy. If $\phi_{z}^{*}=0$, the follower is not affected by leader's pollution; hence, the leader cannot influence foreign pollution by strategically underregulating its own pollution. Since the only strategic

\footnotetext{
${ }^{13}$ Symmetry implies that both countries have the same preferences and technology.

${ }^{14}$ Transboundary pollution may be unidirectional if one country is upstream while the other is downstream along a river. For instance, the Ganges flows from India to Bangladesh, the Indus flows from India to Pakistan, and the Nile flows North from Sudan to Egypt.
} 
interaction between countries is through transboundary pollution, in the absence of bilateral transboundary pollution, both countries set pollution taxes equal to the marginal damage from own pollution. Even in the presence of bilateral transboundary pollution, if the follower's marginal damage from own pollution does not change with the leader's pollution level ${ }^{15}$, i.e., if $\phi_{z^{*} z}^{*}=0$, then the leader is unable to influence the follower's pollution by strategically choosing a lower pollution tax. Thus, the leader sets its pollution tax equal to the marginal damage from own pollution. We summarize these results in the following proposition.

Proposition 2. When countries set domestic environmental policies sequentially, the equilibrium coincides with the simultaneous-move equilibrium and both the leader and follower set their pollution taxes equal to the respective marginal damages from own pollution if either of the following holds:

- at least one of the countries does not suffer from transboundary pollution, i.e., transboundary pollution is either unidirectional or does not occur;

- the follower's marginal damage from own pollution is not affected by the leader's pollution level.

The home country's optimal pollution tax, $t(\alpha, \beta)$ is determined from eq. (15), which can be written as:

$L(t, \beta, \alpha)=t-e_{u} \phi_{z}+e_{u} \phi_{z^{*}}\left(\frac{e_{u^{*}}^{*} \phi_{z^{*} z}^{*} R_{t^{*} t^{*}}^{*}}{1+e_{u^{*}}^{*} \phi_{z^{*} z^{*}}^{*} R_{t^{*} t^{*}}^{*}}\right)=\phi_{z}\left\{\frac{t}{\phi_{z}}-e_{u}+e_{u} \frac{\phi_{z^{*}}}{\phi_{z}}\left[\frac{e_{u^{*}}^{*} \phi_{z^{*} z}^{*} R_{t^{*} t^{*}}^{*}}{1+e_{u^{*}}^{*} \phi_{z^{*} z^{*}}^{*} R_{t^{*} t^{*}}^{*}}\right]\right\}=0$.

The last term [...] in the eq. (16) is independent of $\alpha$. Hence,

Proposition 3. When counties set pollution taxes sequentially,

1. a shift in the leader's pollution damage function, i.e., a change in $\alpha$, such that $\frac{\partial\left(\phi_{z^{*}} / \phi_{z}\right)}{\partial \alpha}>$ 0 will reduce the maximizing ratio of the leader's tax rate to marginal damage from own emissions, i.e., $\frac{\partial\left(t / \phi_{z}\right)}{\partial \alpha}<0$;

2. a shift in the leader's pollution damage function, such that $\frac{\partial \phi_{z}}{\partial \alpha}=0<\frac{\partial \phi_{z^{*}}}{\partial \alpha}$ will reduce the leader's optimal tax rate.

Proof. Both results follow directly from the home country's second order condition.Q.E.D.

\footnotetext{
${ }^{15}$ The pollution damage function $\phi^{*}\left(z, z^{*}\right)=\eta\left(z^{*}+\lambda z\right), \eta, \lambda>0$ satisfies this property.
} 
Intuitively, an increase in the ratio of marginal damage from transboundary pollution to that from own pollution ${ }^{16}$ reduces the leader's ratio of tax rate to own marginal damage because it increases the leader's incentive to underregulate own pollution to reduce the incidence of transboundary pollution.

Finally, we compare total pollution in the sequential and simultaneous move games.

Proposition 4. If pollution is a pure global public bad, then aggregate pollution is higher in the sequential-move game than that in the simultaneous-move game.

Proof. From Proposition 1, we have $t^{*}>\hat{t}^{*}$, i.e., $e_{u^{*}}^{*} \phi_{z^{*}}^{*}\left(z+z^{*}\right)>e_{u^{*}}^{*} \phi_{z^{*}}^{*}\left(\hat{z}+\hat{z}^{*}\right)$. Hence, strict convexity of the pollution damage function implies $\left(z+z^{*}\right)>\left(\hat{z}+\hat{z}^{*}\right)$. $\quad$ Q.E.D.

Thus, when the externality is of a pure public bad nature, setting policies sequentially leads to higher aggregate pollution than setting policies simultaneously.

\section{Concluding Remarks}

Pollution in lakes and rivers shared between countries is a common type of transboundary pollution problem. We analyzed non-cooperative environmental policy between such countries when the only strategic interaction is through transboundary pollution, i.e., the countries are closed or small open economies. We find that when pollution taxes are set sequentially, the leader (follower) sets a lower (higher) pollution tax and total pollution may be higher as compared to the simultaneous-move game. The only motive behind the leader's underregulation of pollution is to induce the follower to set a higher pollution tax and thereby reduce the inflow of transboundary pollution from the follower, i.e., to reduce carbon leakage. Our analysis points out the possibility of carbon leakage even when countries are not large, i.e., they cannot influence world goods prices. An important policy implication of our analysis is the importance of involving all countries, large or small, in environmental agreements since sequential policy setting may lead to higher aggregate pollution.

\footnotetext{
${ }^{16}$ Pollution damage functions of the form: $\phi()=.\gamma\left(z+\alpha z^{*}\right)^{2}$ and $\phi()=.\mu\left(z+\alpha z^{*}\right)+\gamma\left(z+z^{*}\right)^{2}$ would be examples for Propositions 3.1 and 3.2, respectively.
} 


\section{References}

[1] Bárcena-Ruiz, J. C. (2006). Environmental Taxes and First-Mover Advantages. Environmental and Resource Economics, 35, 19-39.

[2] Copeland, B. R. (1996). Pollution content tariffs, environmental rent shifting, and the control of cross-border pollution. Journal of International Economics, 40, 459-476.

[3] Copeland, B. R. and Taylor, M. S. (2004). Trade, Growth and the Environment. Journal of Economic Literature, 42(1), 7-71.

[4] Gal-Or, E. (1985). First Mover and Second Mover Advantages. International Economic Review, 26, 279-292.

[5] Hatzipanayotou, P., Lahiri, S. and Michael. M. S. (2008). Cross-Border Pollution, Terms of Trade and Welfare. Environmental and Resource Economics, 41(3), 327-345.

[6] Kennedy, P. W. (1994). Equilibrium Pollution Taxes in Open Economies with Imperfect Competition. Journal of Envrironmental Economics and Management, 27, 49-63.

[7] Kiyono, K. and Okuno-Fujiwara, M. (2003). Domestic and international strategic interactions in environment policy formation. Economic Theory, 21, 613-633.

[8] Lapan, H. E. and Sikdar, S. (2010). Strategic Environmental Policy under Free Trade with Transboundary Pollution. Review of Development Economics, forthcoming.

[9] Markusen, J. R. (1975). Cooperative Control of International Pollution and Common Property Resources. Quarterly Journal of Economics, 89(4), 618-632.

[10] Raucher, M. (1997). International Trade, Factor Movements and the Environment. Claredon Press, Oxford.

[11] Tirole, J. (1989). The Theory of Industrial Organization. Cambridge and London: The MIT Press. 